\title{
TETRALOGÍA DE LA SOLEDAD: INTRODUCCIÓN A LA NARRATIVA DE JAVIER TOMEO
}

\author{
José María Pozuelo Yvancos \\ Universidad de Murcia
}

\section{Contexto}

La revista Ínsula, en su número de septiembre de 1990, dedicó una veintena de páginas al «Estado de la cuestión» de la novela española en los dos últimos años. Reunió allí opiniones de diversos profesores y críticos sobre las líneas predominantes en la actual narrativa y sobre sus valores y limitaciones. Sin comunicación entre sí, las opiniones de los siguientes críticos: A. Amorós, A. Basanta, R. Conte, Carlos Galán, J. Goñi, R. Gullón, Manuel Longares, Juan Oleza y C. Rodríguez Fer tienen muchos puntos en común y, al ofrecer significativas coincidencias, hacen más fiable su diagnóstico, mucho más cuando algunas de las conclusiones compartidas vienen a redundar sobre las que vertieran hace muy poco Darío Villanueva en su revisión para Letras Españolas (19791989) de Editorial Castalia y Santos Sanz Villanueva en el capítulo «Últimos narradores españoles»!

Una primera conclusión de estos informes es la dificultad para trazar perfiles nítidos de tendencias, como si faltasen ahora ejes claros para el agrupamiento de los novelistas en escuelas, estilos, géneros temáticos o tonalidades. Aunque buena parte de esa dificultad cabe atribuirla a la falta de perspectiva histórica que hace imposible el dibujo de un corpus cuando se está históricamente muy próximo a él, o, lo que es lo mismo, cuando la selección necesaria de las líneas de fuerza aún no se ha producido, no todo puede sancio-

1.- Dario Villanueva: «La novela» en Letras españolas (1979-1989), Madrid, Castalia, 1990, y Santos Sanz Villanueva: «Últimos narradores españoles» en Las nuevas letras n.o 6, Almería, Verano, 1986. 


\section{JOSÉ MARÍA POZUELO YVANCOS}

narse como un problema de método. Aunque echemos en falta, y no puede ser de otro modo, una óptica particular de selección, que no podrá ofrecer garantías hasta pasada al menos una década, hemos de reconocer que buena parte de las dificultades pertenecen no al método sino a la índole misma del objeto - la novela española de los ochenta-, que contiene un conjunto de características comunes, pero que pudieran algunas hacer fracasar cualquier intento de clasificación. Tres rasgos de ese conjunto colaboran para la diagnosis inicial de variedad multiforme. 1. La superproducción editorial, 2. Voluntad de ruptura con la tradición anterior y 3 . Una enorme variedad temática y estilística.

Glosaré brevemente estos rasgos y, aunque lo haré en contigüidad sucesiva, hay que comenzar por afirmar su interdependencia, puesto que unos inciden sobre los otros y a la vez se deducen de ellos.

1. El fenómeno de la superproducción narrativa en estos cuatro o cinco últimos años no es solamente un dato constatable en términos de número, crecido y abrumador, de novelas publicadas, sino que es también un fenómeno explicable como consecuencia de la situación nueva de la producción editorial que ha hecho indisoluble ya la literatura y el mercado. Digo esto porque estimo que la influencia poderosa de los valores de consumo no puede entenderse únicamente afecta a parámetros cuantitativos, lo que apenas tendría consecuencias negativas, sino que incide muy notablemente en el sesgo mismo con que la literatura es concebida, escrita y leída. Hay ya una bibliografía crítica muy sobresalicnte, de la que fucron pioncros los trabajos dc Robcrt Escarpit, para estudiar el fenómeno de la influencia de los media en la propia fisonomía del género novela. La conclusión obvia es que una novela no es primero y luego se publica y finalmente se consume, sino que su consumo previsible es la que la convierte en publicable y esta circunstancia - decisiva hoy - afecta a la propia concepción que los autores hacen de su obra, su adaptación al gusto y directrices de una editorial y presumiblemente, pero sólo por el intermedio inevitable de ésta, de un público lector. Darío Villanueva acuñó el subtítulo de "A la búsqueda del best-seller» para dar cuenta de esta situación en la novela actual española, cuyo análisis excede metodológica y temáticamente los propósitos de esta breve contextualización de la narrativa de Javier Tomeo, pero explicará alguno de sus rasgos 1 bis.

El fenómeno de superproducción ha afectado también a la dificultad de la propia historia literaria para definir perfiles. Dos libros recientes dedicados a la cuestión, el de Santos Alonso, La novela en la transición, y el de Dolores Asís Garrote, Última hora de la novela en España ${ }^{2}$, creo que representan la constatación definitiva de la falta de necesaria perspectiva a la que antes me referí, toda vez que las novelas citadas y analizadas en ambos libros superan los tres centenares y ello para la novela seleccionada o de autor, merecedora de atención para el profesor universitario y para los últimos diez años tan sólo.

De lo cuantitativo a lo cualitativo: de la masiva producción y de la búsqueda del consumo también masivo se viene a desgajar tanto la protuberancia de lo que se ha convenido en llamar literatura ligth, de usar y tirar, como una acusada precipitación,

1 bis.- El libro de Ramón Acín: Narrativa o consumo literario (1975-1987), Zaragoza, P.U.Z., 1990, aborda monográficamente la relación entre novela española de hoy y consumo literario. A él remito al lector interesado en profundizar en la problemática aquí esbozada.

2.- Santos Alonso: La novela en la transición, Madrid, Puerta del Sol Ensayo, 1983, y Dolores Asís Garrote: Última hora de la novela en España, Madrid, Universidad Complutense, 1990. 
perceptible en la misma escritura. A. Amorós, A. Basanta, C. Galán, J. Goñi y Joan Oleza, por separado, han coincidido en denunciar que se observa en las novelas con excesiva frecuencia un apresuramiento: «Sugerir, más que contar en ciento y pico folios mejor que en trescientos, a lo claro y a lo directo... los novelistas de hoy parecen encontrarse demasiado cómodos en la media distancia. Parecen sus libros — no todos pero sí bastantes - novelas cortas, historias rematadas con prisas... novelas a las que les falta ambición, dedicación; hay libros que parece que se los han arrancado de las manos -en un momento de distracción-sus agentes para ofrecerlos a editores/premios» ${ }^{3}$. Andrés Amorós y A. Basanta urgen al novelista a saber esperar, a dedicar el tiempo necesario a sus novelas y lamentan el mucho fárrago y escasa calidad de la escritura.

Otra, al mismo tiempo causa y por otra parte efecto de esta superproducción, es el carácter fungible de los títulos. Darío Villanueva lo constataba: difícilmente permanecen, no ya en las librerías, ni tan siquiera en el catálogo editorial, novelas lanzadas por un breve tiempo a bombo y platillo y de inmediato descolgadas, en ciclos de pocos años, cada vez más breves, de la oferta, con lo que resulta difícil incluso el sosiego crítico necesario. Y una última causa-efecto de tal superproducción: la novela de los últimos años ha buscado el mayor interés del lector, reconciliarse con el público, lo que, al tiempo que ha propinado saludables rupturas con pseudovanguardismos y piruetas formales o manierismos crípticos, ha influido negativamente en una cierta tendencia acomodaticia a la explotación y repetición de fórmulas ya consabidas, cuando éstas han demostrado tener éxito. Joan Oleza veía la limitación de un excesivo recurso a la novela de género, con repetición casi automática de esquemas conocidos y sin la valentía necesaria para modificarlos o transgredirlos. Este acomodarse a lo previsible para no espantar al lector ha propinado una cierta reducción de ambiciones y de planteamientos narrativos, en palabras de Oleza: «espacios planos como decorados, tiempos reducidos, avara nómina de personajes, intriga unilateral y descontextualizada, temática unívoca, conflictos ni motivados ni historiados"».

2. Propuse como segundo rasgo una cierta ruptura de la novela de hoy para con la tradición anterior, sobre todo para con aquélla imperante hasta la segunda mitad de la década de los setenta. Tal ruptura ha traído una ausencia de dogmas y la conciencia clara de hallarse los novelistas en una transición en la que ninguna consigna estética o ideológica parece constreñirles. Como quiera que la influencia más poderosa sobre la gencración inmediatamente anterior la ejerciera el vanguardismo formalista y la experimentación de nuevos espacios estilísticos, la novela de hoy parece querer desasirse de esa influencia y prefiere conseguir al público para sí a la educación del público en nuevos esquemas renovadores, que, también es cierto, habían ofrecido sitio, en la década de los setenta, a experimentalismos no siempre eficaces y muchas veces tan sólo pirotécnicos. Decididos a incorporar a menudo algunos de aquellos logros, han reaccionado empero contra las derivaciones extremas de la muerte de la historia y de la dislocación estructural, en espacios y tiempos, que las novelas inspiradas o en la línea del nouveau roman prodigaron en los años sesenta y setenta.

Si un polo de gravitación había sido el experimentalismo formalista de la novela que Gonzalo Sobejano acertó en llamar por eso estructuralista ${ }^{4}$, el otro polo de gravitación

3.- J. Oleza: «El estado de la cuestión. Novela española 1989-1990», Insula, septiembre 1990, pág. 11.

4.- Gonzalo Sobejano: Novela española de nuestro tiempo, Madrid, Prensa Española, 1975, 2. ${ }^{\text {a }}$ Edición. 
era para la novela anterior el «problema de España» o más exactamente la vinculación de la novela al compromiso social, que obtuvo netas corrientes de realismo en la década de los cincuenta, pero que se había proyectado inevitablemente hasta la tardía muerte de Franco en 1975. Si en las décadas anteriores eran claramente perceptibles estas dos líneas, la experimentalista y la social, evidenciando ambas distintas formas de actitud «comprometida», los novelistas que publican en los años ochenta han preterido tanto un acento como el otro. Aunque siempre hay excepciones, ha sido evidente un cambio temático y de escenario hacia las zonas de la novela urbana, teñidas de cosmopolitismo culturalista con predominancia sobre el realismo rural, o también una constante explotación de la problemática individual del habitante de la ciudad, sometido a la soledad. No parece que los novelistas de hoy se entreguen a reflejar los problemas comúnmente llamados sociales. Joan Oleza se refería al significativo silencio que la novela había hecho sobre el fenómeno de la transición política, y ello es sólo un ejemplo de la tendencia a enfocar al individuo en términos más existenciales que sociales. Ello predomina, cuando no se adscriben a la explotación de los géneros de moda, como el policiaco de la novela negra, el lírico o el imaginativo-fantástico. Quizá se podría unificar esta doble reacción antivanguardista y contrarrealista dentro de un marbete que Oleza propone denominar realismo abierto: «una fórmula novelesca que construye y deconstruye simultáneamente una imagen de la realidad, que sitúa a la ficción y al contexto histórico frente a frente para poder jugar con sus conexiones, que si elabora una imagen del mundo no es porque se pretenda fiel al mundo, sino justamente porque le es infiel, y abre lo real a dimensiones extranaturales, lo transgrede en dirección al lirismo (A. García Morales), a lo imaginario (J. M. Merino) o al ludismo (E. Mendoza)» 5 .

3. Porque, en efecto, y llegamos al tercer rasgo con que cerraré esta apresurada contextualización general, la novela española de hoy ha repartido mucho sus tonalidades, géneros y temática hasta configurar una vasta policromía de accesos a diferentes perfiles y dibujos de la realidad. Las novelas en sí mismas no suelen tener planteamientos polifónicos, al modo como acuñara el concepto Mijaíl Bajtín, pero sí es polifónico el conjunto de ellas, inmerso en tal variedad que se hace difícil una clasificación más allá de los grandes hitos cronológicos de las décadas. Si la variedad de registros hace imposible cualquier predominancia, también es por riqueza de caminos, aunque cabría decir que hay menos exploraciones que repeticiones: el esquema policiaco (con frecuentes guiños a la novela negra norteamericana), la novela lírica, la novela histórica, el memorialismo introspectivo. Un panorama que R. Conte califica de disperso, caótico y profundamente libre.

\section{La narrativa de un autor prolífico: J. Tomeo}

La obra narrativa de Javier Tomeo, de la que este artículo tan sólo estudiará una parte, emerge con perfiles personales de clara singularidad, aunque en justa medida es deudataria del contexto anteriormente presentado. Explica esta deuda la circunstancia de ser al mismo tiempo un autor prolífico y de tardío reconocimiento, lo que ha propiciado una singular desproporción entre lo publicado por él antes del éxito editorial de Amado monstruo (1985) y la cantidad de novelas que se sucederían en los muy pocos años posteriores a esta consagración. En efecto, posteriores a 1985 son El cazador de leones

5.- Joan Oleza: «El estado...», cit., pág. 11. 


\section{TETRALOGÍA DE LA SOLEDAD}

(1987), La ciudad de las palomas (1989), Historias mínimas (1989), Bestiario (1989), El mayordomo miope (1989), Problemas oculares (1990), El gallitigre (1990), El discutido testamento de Gastón de Puypalier (1990). Entre su primera novela, aparecida ya en 1967, El cazador, y 1985, esto es, en dieciocho años publica cinco volúmenes ${ }^{6}$ y en cambio aparecen en tan sólo los últimos seis años ocho obras narrativas, seis de las cuales son novelas. Tamaña desproporción revela bien cuanto dijimos de la superproducción narrativa urgida por circunstancias de éxito editorial y algo podría adelantarse respecto a la vorágine publicadora en que el propio autor puede verse inmerso, hasta el extremo de hacernos sospechar - por la naturaleza de algunas entregas - que la imprenta ha conocido obras que para el autor habrían sido postergadas o incluso silenciadas de no mediar tan abrumador éxito editorial en España y en el extranjero, pues Tomeo ha tenido también fortuna en la aceptación de sus traducciones a varias lenguas.

No es mi propósito en este artículo estudiar la totalidad de su obra narrativa, lo que exigiría mayor espacio, otros vehículos y seguramente otro conductor. Pero sí quisiera adelantar una justificación de la elección de mi objeto de estudio, que se limitará a cuatro de sus novelas, las publicadas entre 1979 y 1989. Concretamente analizaré El castillo de la carta cifrada (1979), Amado monstruo (1985), El cazador de leones (1987) y La ciudad de las palomas (1989). La elección, que implica también una selección, de este breve conjunto de títulos obedece a razones que descansan en el propio corpus y a razones que se apoyan en mi valoración estética. Respecto a lo segundo entiendo que con estas cuatro novelas ha entregado Javier Tomeo lo mejor de su contribución hasta el momento. Forman en efecto estas cuatro novelas un punto de notable calidad artística que estimo cimero de su producción narrativa. En lo que se refiere a lo primero, las razones objetivas del corpus, veo estas cuatro novelas como entregas diferentes dentro de un mismo proyecto narrativo que puede recibir tratamiento unitario, porque, desde un punto de vista temático y estilístico, configuran una unidad que he dado en llamar tetralogía de la soledad.

\section{Intertextualidad en la Tetralogía}

Hay coincidencias de orden discursivo y semántico, perceptibles pronto por el lector, en las cuatro novelas a las que he propuesto considerar tetralogía. A esos órdenes discursivo y semántico me referiré más adelante. Antes quiero referirme a que la unidad del proyecto narrativo de las novelas de la tetralogía no es sólo un «a posteriori» que el lector o crítico puede deducir. Hay una constante comunicación de cada una de estas cuatro novelas con las demás que añadir a sus muchos parecidos semánticos y de ordenación discursiva. Me refiero singularmente a los cuidados guiños que el autor ha hecho a su lector mediante la inclusión en cada libro de algún elemento intertextual que se refiere directamente a los otros miembros de la tetralogía, reforzando de ese modo aquella impresión de unidad. Como se sabe, Cesare Segre introdujo una oportuna distinción metodológica a la discusión del concepto bajtiniano de intertextualidad, que ayudó mucho a limitar y precisar el concepto ${ }^{7}$, para que no alcanzase la dilatada proyección que quisieron hacerle obtener Roland Barthes y Julia Kristeva hasta prácticamente inutilizarlo, como Claudio Guillén

6.- Ceguera al azul, 1969 (reeditada en 1986 con el título de Preparativos de viaje), El Unicornio (1971), Los enemigos (1974), Diálogo en re mayor (1976), El castillo de la carta cifrada (1979).

7.- Cesare Segre: Teatro e romanzo, Turín, Einaudi, 1984, págs. 103-108. 


\section{JOSÉ MARÍA POZUELO YVANCOS}

denunciara ${ }^{8}$. Hay, sirviéndome de la distinción de Segre del concepto de interdiscursividad, muchos elementos interdiscursivos, de proximidad o eco en estas cuatro novelas. No podía ser de otro modo tratándose de novelas sucesivas y entre las que median tan sólo diez años entre la primera y la última y cuatro años entre las tres últimas. Sin que podamos aislar siempre sentencias de recuerdo netamente intertextual pero sí de familiaridad interdiscursiva, encontramos en las cuatro novelas reiteraciones constantes de motivos sobre la soledad de sus héroes, encerrados física y espiritualmente, fuertemente desarraigados de su medio. Ésta no es siempre una propiedad interdiscursiva, sino semánlica, y será analizada más adelante. Pero ocurre que esta circunstancia es allegada siempre por cada personaje en frases que de modo explícito se refieren a ese encontrarse solos, hasta llegar a la radical manifestación simbólica de La ciudad de las palomas, cuyo protagonista, inexplicablemente, queda solo en una ciudad vacía únicamente comunicado por un teléfono sin respuesta y un ordenador que acaba por no funcionar, rodeado de unas palomas que se ciernen amenazadoras sobre su entorno. En El castillo de la carta cifiada es un marqués que vive aislado desde hace más de veinte años y que manifiesta constantemente su radical soledad en frases hondamente conmovedoras y muy eficaces, porque advienen en contextos de fuerte teatralidad irónica y se destacan por nosotros emotivas por su fuerte tonalidad lírica. En Amado monstruo y en El cazador de leones, sus protagonistas, que resultan finalmente el mismo, están patológicamente incomunicados en una habitación de su casa, protegidos por la obsesiva manía de su madre y sin otra comunicación con los demás que la lectura. En todas las novelas citadas los protagonistas recurren a patéticas declaraciones sobre su soledad, repetidas una y otra vez, y el lector inmediatamente las identifica como leit motiv.

Junto a las frases en que los héroes declaran soledad hay otros elementos interdiscursivos en las cuatro novelas, como la presencia de una lluvia tenue pero pertinaz, constantemente reiterada y aludida en las cuatro novelas, y que configura un telón de fondo dentro de un decorado de creciente melancolfa. En Amado monstruo hay ocho referencias a la lluvia, cinco de ellas a partir de la página 42, una lluvia que cada vez es más intensa, gratuita y eficazmente conectada con la creciente atmósfera de tensión y radical soledad de los protagonistas de la novela. En El cazador de leones vuelve a insistirse sobre la lluvia mansa y pertinaz que resuena desoladora en el patio de luces, único hueco del exterior al que asoma un personaje encerrado en una habitación repleta de libros sobre viajes fantásticos. En La ciudad de las palomas hay cuatro referencias al menos a la lluvia en contextos fuertemente atravesados por una gran tristeza y soledad, respecto a las cuales, como siempre en Tomeo, la otoñal lluvia, mansa y tenue, pero pertinaz, resulta metonímica.

Hay guiños concretos al lector, esta vez sí netamente intertextuales y conscientemente allegados, como el chiste que se ofrece en la página 65 de El castillo de la carta cifrada sobre que si la lluvia cayera de abajo arriba habríamos de llevar el paraguas al revés. Tanto esa agudeza cuanto el fondo contextual sobre lo democrático de la lluvia es repetida, tal cual en El cazador de leones (p. 66) y aludida en Amado monstruo. También tienen El castillo... y El cazador... constantes referencias a los animales en largas disertaciones que en una y otra novela aparecen sobre los insectos, las ranas, los leones o las hienas. Por debajo de la notable excentricidad de las reflexiones sobre las capacidades de los animales para soportar sus trágicos destinos late en ambos libros el mismo pensamiento;

8.- C. Guillén: Lo uno y lo diverso. Introducción a la Literatura Comparada, Barcelona, Crítica, 1985, págs. 309-327. 
la soledad del hombre contrasta fuertemente con la íntima correspondencia que los miembros de las sociedades animales tienen entre sí, pero además está vivamente acentuada la radical incapacidad del hombre para comunicarse con ellos y para participar en la que como sintagma explícito en ambas se presenta como la "confraternización universal». En otras obras ajenas a esta tetralogía, como Bestiario y El gallitigre, se insiste en idéntico pensamiento. Tan romántica conclusión, la gratuidad del hombre para con su medio natural y el deseo de ser sus protagonistas menos contingentes y gratuitos para con ese medio, está sabiamente dosificada al venir entreverada en un clima de bromas-veras, en que los personajes de tales libros son excéntricos, aparentemente locos y manifiestan una obsesión casi maniática por el medio animal pero de la que se desgajan reflexiones de hondo calado existencial.

La comunicación intertextual entre las novelas de la tetralogía es manifiesta cuando se trata de ciertas recurrencias tanto a situaciones concretas como a la identidad del pcrsonajc protagonista, que resulta ser la misma en Amado monstruo y El cazador de leones. El detalle de su tara física, tener seis dedos en cada mano, es de singular importancia en la fábula de Amado monstruo. Se descubre al final y se conoce finalmente motivo generador tanto de la enfermedad psíquica del protagonista como de la obsesiva sobreprotección de la madre. Es motivo tan central en la construcción de la fábula de esta novela que desencadenará su final abrupto y la conclusión de la inaceptable singularidad del tarado para con los valores de la empresa a cuyo trabajo aspira. Volveremos luego sobre este asunto. Para el juego de intertextualidad entre las novelas de la tetralogía que vengo analizando, importa retener que la significación central de esa tara física, y su ordenación final como elemento desencadenante del desenlace, es repetida en El cazador de leones. En la página 74 de esta novela dice Duvalier, su protagonista:

Yo también tuve un primo con una madre imposible... Apenas podía salir solo de su casa y hasta que hubo cumplido los treinta años no pudo fumar en presencia de mi tía. Mi primo tenía seis dedos en cada mano y su madre decía que los niños con seis dedos no pueden ir solos por el mundo... No, no señorita, la historia de mi primo es real, no la he sacado de ninguna novela. Si usted acaba de leer un libro que cuenta una historia idéntica no es culpa mía, se trata de una simple coincidencia...

Más adelante, cuando Duvalier está ya decididamente entregado a mostrar a su interlocutora todas sus ocultas intenciones y se desencadenan los reproches que permiten deshacer la fícción que sobre sí mismo ha creado, añade:

Sí, sí, señora mía, ha oído usted bien, no tengo ya ningún incoveniente en confesárselo: yo soy quien tiene seis dedos en cada mano, como el protagonista de la novela de la que me habló antes. Puede incluso que yo sea ese protagonista... (p. 94).

Para el lector de Amado monstruo que lea posteriormente El cazador de leones tamaña recurrencia obtiene una significación más trascendental que el mero guiño intertextual: adquiere la consciencia de que ambas novelas, cuyo planteamiento discursivoformal es además, como veremos luego, muy semejante, son episodios de una misma historia de significación recurrente, como también veremos.

Las otras novelas de la tetralogía comunican asimismo intertextualmente con estas dos. En La ciudad de las palomas, Teodoro, su personaje protagonista (y casi solo personaje, como ocurre en las demás) juega con su ordenador y en un momento apunta el 


\section{JOSÉ MARÍA POZUELO YVANCOS}

narrador: «Ahora, por ejemplo, renuncia a los marcianos; se convierte en cazador de leones y la pantalla de cristal líquido se llena de palmeras» (pág. 9). También esta novela coincide con El cazador de leones en el lugar que ocupa el teléfono. Teodoro, en una ciudad vacía, busca desesperadamente una comunicación que no llega a producirse, pero que sistemáticamente persigue con la esperanza de hallar una voz con la que salir de su asfixiante soledad. En una de sus aleatorias llamadas, obtiene respuesta de un contestador automático: "Una voz de mujer le invita a dejar grabado el mensaje. Es, sin lugar a dudas, la voz más hermosa que ha oído en su vida [requiebro que también hace Duvalier en El cazador de leones a su interlocutora], así que decide marcar varias veces el mismo número para seguir escuchándola. Luego empieza a perder su capacidad de ensoñación...» (pág. 74). Más adelante hay otra referencia a esa voz y una actitud que recuerda mucho al personaje de la anterior novela en la teatralidad de la declaración amorosa y en el fondo de su significado: «Vuelve luego la mirada al teléfono y piensa en la dulce voz que encontró antes en el contestador automático. Si supiese donde está esa mujer (se dice) iría ahora mismo a buscarla. Me arrodillaría a sus pies y me pasaría toda la noche hablándole de amor» (pág. 91).

Los fenómenos, interdiscursivos unas veces y netamente intertextuales otras, han mostrado una constante permeabilidad entre las cuatro novelas objeto de este estudio, al tiempo que han aparecido ya algunos de los rasgos más característicos de su mundo: personajes aislados, con taras físicas y maniáticos obsesivos en una atmósfera de vacío. Como veremos enseguida, el planteamiento discursivo - singularmente los pactos narrativos de las cuatro novelas y el uso de la temporalidad - va a acentuar su carácter unitario del que las conexiones hasta ahora analizadas son una manifestación más superficial pero no menos interesante en orden a valorar la tetralogía como un proyecto narrativo continuado.

\section{La dimensión discursiva I: pactos narrativos. Temporalidad}

La primera característica que todo lector advierte de inmediato en las novelas de Tomeo es su dimensión. Todas son muy cortas y hasta podría aventurarse que han sido medidas con escrupulosidad porque, como ocurre también con toda su producción novelística en las que incluyo dentro de la que llamo tetralogía, publicada toda ella en editorial Anagrama, el número de páginas es casi el mismo: 111 en El castillo de la carta cifrada, 111 páginas asimismo en Amado monstruo, 95 en El cazador de leones y 117 en La ciudad de las palomas. Novelas todas en torno a cien páginas. Decía I. Lotman que el espacio y el cierre previsto como elemento de la espacialización narrativa es uno de los principios generadores de la estructura textual ${ }^{9}$ y al hacerlo daba una clave para la interpretación unitaria de muchos problemas discursivos. En efecto, las cuatro novelas no coinciden únicamente en esa cantidad de páginas, sino que también y por ella misma, según Lotman subrayara, la estructura textual discursiva muestra un carácter concentrado, limitado al desarrollo intensivo de una anécdota, ocurrida a muy pocos personajes en un espacio físico muy reducido y con casi idéntica modalidad del discurso por cuanto casi todas esas novelas (tres de cuatro) son la narración de un diálogo en el que solamente interviene elocutivamente uno de los interlocutores, en una fórmula que podríamos calificar de mono-diálogo.

En efecto, el pacto narrativo propuesto en tres de estas novelas, concretamente en El

9.- I. Lotman: Estructura del texto artistico, Madrid, Istmo, 1978, pág. 261. 
castillo.... Amado monstruo y El cazador de leones, es muy semejante y en la primera y tercera prácticamente idéntico. Tanto El castillo... como El cazador... proponen la narración de un diálogo ya en su primera página, pero del que solamente se ofrece, luego de una leve acotación narrativa, la intervención de uno de sus interlocutores:

No se preocupe, Bautista, y deje de temblar - me dijo aquella mañana el señor Marqués - lo que voy a encargarle es fácil... (El castillo..., pág. 9).

Bautista, el mayordomo que esta acotación narrativa presenta como el narrador, ya no vuelve a tener intervención alguna, narrativa me refiero, porque su intervención será la de interlocutor silencioso del gran monólogo del marqués, reproducido en estilo directo que ocupa todo el resto de la novela y que, como se ha visto, narra, a modo de cita, el propio mayordomo.

Del mismo modo, El cazador de leones es la representación de un diálogo telefónico cntrc Duvalicr y su intcrlocutora del que solamente se ofrece, tras una breve acotación narrativa de discurso atributivo al comienzo de la novela, la intervención locutiva del protagonista, en estilo directo. Sólo por lo dicho por el personaje Duvalier, como en El castillo... ocurriera con lo dicho por el Marqués; sabemos de las reacciones e intervenciones de sus interlocutores, Nicolasa y Bautista respectivamente, en una y otra novela. Así comienza El cazador de leones:

Buenas noches - dice el hombre apenas le parece escuchar al otro lado del teléfono la voz de la mujer- perdone usted mi atrevimiento. Puede que ya no se acuerde de mí... Me llamo Armando Duvalier... etc. (p. 9).

Como se observa, hay en ambas novelas una acotación narrativa, homodiegética para el caso del narrador, Bautista, y heterodiegética en el narrador de El cazador... La funcionalidad de estas leves intervenciones del narrador en lo que podría simplemente haberse ofrecido como diálogos representados del todo y no narrativamente atribuidos o presentados se debe al diferente estatuto de realidad que ofrecen las palabras según sean sólo palabras de los personajes - dramatizadas - o tengan la vericidad de sanción real externa a ellas que les proporciona la instancia narrativa, responsable final de una historia, que no es, por ello mismo, simple y disparatado monólogo sin raíz imaginativa, sino narración verosímil (novela) de un diálogo habido una vez por unos personajes a los que el acto narrativo otorga dimensión de versosimilitud y el narrador reclama fiabilidad. Sabemos por el narrador que el diálogo tenido por Duvalier no es el monólogo imaginado por un loco que habla solo. También para situar el marco dialogizante y no monologal del discurso de ambas novelas se ha introducido esa leve acotación narrativa que basta ella sola para presentar a los dos únicos personajes del diálogo en esas novelas: Bautista, que escucha al Marqués y, presumiblemente, según deducimos de las referencias de éste, le contesta o sugiere, pregunta y expresa temores. Las mismas acciones ilocutivas que cumple la interlocutora de Duvalier en la otra novela. Creo que ambas explicaciones son importantes: la del marco y la del estatuto de mayor vericidad que ontológicamente cabe deducir de las palabras de un narrador para ser lo leído novela y no palabras de personajes sin fuente externa y superior de discurso, y ambas sirven para explicar la función de la levísima y única presencia de la instancia narrador, en ambas novelas, reducida esa presencia, insisto, a la frase citada.

En el caso de Amado monstruo la situación narrativa es muy semejante, aunque esta vez no idéntica, a aquellas dos novelas. En ésta nos encontramos con la narración de una escena, con elementos fundamentalmente dialogados, pero no exclusivamente, que el 


\section{JOSÉ MARÍA POZUELO YVANCOS}

protagonista, Juan D., cuenta. La historia vuelve a ser la de un diálogo entre dos personas - y ahí radica su semejanza con las otras dos novelas - pero en este caso no es un monólogo en estilo directo, sino una narración en la que toda información -incluso la locucional del llamado por G. Genette récit de paroles ${ }^{10}$ - se canaliza por la narración homodiegética con privilegio para el estilo indirecto, aunque con numerosísimas representaciones de estilo cuasi directo, de estilo directo libre y de estilo indirecto parcialmente mimético, según la tipología que sobre las de MacHale y Mario Rojas propuse en mi libro Teoria del lenguaje literario ${ }^{11}$. Aunque discursivamente, en cuanto modalidad del decir y en cuanto al volumen narrativo, Amado monstruo se separe de las otras dos, no debe olvidarse que se trata en esta novela, como en aquellas que cronológicamente le siguen, de un mismo esquema o situación en el nivel de las acciones y de los personajes: la narración de un diálogo entre dos personas, aunque en Amado monstruo sea un diálogo en su totalidad canalizado por el narrador y en las otras dos novelas se represente en estilo directo lo dicho por un interlocutor y sólo a su través se ofrezcan indicios de las intervenciones del otro. También en Amado monstruo, las intervenciones de Krugger, el jefe de personal que entrevista a Juan D., son canalizadas desde la perspectiva de éste. Todo apunta, por tanto, a que en el nivel funcional y actancial y en parte en el discursivo (en lo que afecta a focalización y temporalidad) hay una semejanza de las tres primeras novelas de la tetralogía.

No tiene interés esta semejanza y tal planteamiento discursivo por su sola unidad con las otras novelas. Creo que mayor importancia tiene la configuración con tal situación narrativa de lo que podríamos calificar siguiendo a Tinianov y Jakobson el principio de la dominante en la estructura de estas novelas: la representación del decir, la verbalización narrativa de la locución directa, es el elemento que mejor caracteriza a Tomeo. El centro, el eje estructurador dominante de sus estructuras narrativas, es el diálogo, de ahí que puede decirse que sus novelas son cuasi teatralizaciones y que algunas hayan tenido fortuna en su versión teatral. Pero pongamos cuidado en advertir que no son teatro sino teatralizaciones, por la dimensión que en sus novelas adquiere, por ejemplo en Amado monstruo, la parcialísima focalización narrativa de Juan D., que en modo alguno podría obviarse, porque representa uno de los centros de mayor interés, como focalización de personaje en términos de narración, tanto de la estructura discursiva como de la significación de esa novela.

Entiendo, por tanto, que la locuacidad y el juego de teatralización que lleva a una difícil pero constante entrega a la verbalización del estilo directo (ya sea narrado, como lo es en Amado monstruo, ya sea propiamente estilo directo, como lo es en las otras dos novelas) es el eje dominante de su estructura discursiva y quizá el rasgo que mejor individualiza a Javier Tomeo en el panorama de la actual narrativa; ningún narrador actual domina como él los registros del diálogo y las mil y una piruetas, embragues, locuciones y modismos coloquiales, con lo que es capaz de atrapar la atención del lector para novelas de cien páginas en que apenas hay otra cosa que un constante flujo verbal en torno a una historia mínima, pero continuamente abierta y amplificada por esa incontinencia verbal de sus protagonistas. Se somete Tomeo a un desafío en el propio estrecho margen que tales situaciones narrativas le proporcionan y hay que decir que sale airoso de él.

10.- A lo largo de este estudio utilizaré la terminología narratológica en el sentido acuñado por Gérard Genette en Figures III, París, Seuil, 1972, y en Nouveau discours du récit, París, Seuil, 1983. 11.- José María Pozuelo Yvancos: Teoría del lenguaje literario, Madrid, Cátedra, 1988, págs. 254256. 
He dejado fuera, porque su pacto narrativo la convierte en diferente, a La ciudad de las palomas; es novela ésta en el que el diálogo no interviene. Se trata aquí de una narración más convencional, de una historia en que un narrador heterodiegético la cuenta en estilo indirecto - que no se abandona en toda la novela salvo leves representaciones de monólogo interior o de monólogo representado. Discursivamente, pues, hay gran diferencia de esta novela con las otras tres, si bien otros elementos semánticos e interdiscursivos la aproximan y justifican su inclusión como miembro de la tetralogía, singularmente destaco el espacio simbólico del protagonista, aislado, incomunicado e incomunicable en una ciudad insolidaria donde únicamente vive soledad. Para esta novela es estilísticamente dominante la temporalidad del presente simultáneo, como tiempo narrativo que visualiza o actualiza en presente, como si emergieran en sincronía, las acciones y su representación discursiva: «Teodoro salta de la cama... se prepara... se sienta... camina... piensay etc. Todo este discurso presentativo en el que el aoristo como tiempo de la narración está ausente acerca su discurso a una representación visualizada en que historia y discurso emergen simultáneos y proporciona índices notables de dramatización, por la actualidad vivenciada de las acciones y de su narración.

Un segundo elemento configurador de la estructura reducida e intensa - del espacio breve, acotado y desarrollado en intensidad y frecuencia- es el uso de la temporalidad en las cuatro novelas. Todas desarrollan una rama de ese tronco unitario que el espacio de su dimensión configura; en cien páginas se desarrolla o bien un diálogo cuya vitesse (o durée) es casi isócrona entre la historia y el discurso; en Amado monstruo dos horas de conversación medidas con escrupulosa puntualidad, aproximadamente el tiempo que dura la lectura de la novela en condiciones normales, y una isocronía total en los casos en los que se ofrece la narración representada en estilo directo de un diálogo, esto es, en $E l$ castillo... y en El cazador de leones. En el caso de La ciudad de las palomas el espacio temporal es también muy reducido, unos tres días medidos con obsesiva puntualidad que modula la sucesión estructurada de las acciones en esos tres días. Son, por consiguiente, las cuatro novelas piezas de relojería en cuanto a la administración del tiempo se refiere en las que bien el narrador, bien el locutor, van marcando la pauta de su devenir con meticulosa frecuencia. Porque Tomeo puede salvar el desafío que él mismo se ha impuesto al proponer un mundo narrativo tan reducido en personajes, en posibilidad y variedad de discursos, y lo hace mediante una vigilancia constante de los ritmos, de modo que la acción principal - la breve anécdota que en cada una de esas novelas se narra-y las constantes digresiones que colorean su fábula, no obtengan desproporciones llamativas. Esta propiedad de medición de las digresiones es particularmente visible en El cazador de leones y El castillo de la carta cifrada, donde el diálogo presente abre constantes digresiones y analepsis narrativas, comentarios y disquisiciones que, al tiempo que invitan a una evasión del nudo central, podrían haberlo dañado, si no se hubiesen visto sometidos a estrecha vigilancia, mucho más conseguida en $E l$ cazador... que en El castillo... donde algunas disquisiciones sobre animales, pero sobre todo sobre posibles alternativas para los hipotéticos asaltantes, se vuelven enfadosas y lesionan algo el conjunto. Amado monstruo alcanza cotas muy altas de organización del ritmo narrativo al seguir escrupulosamente los ritmos de una entrevista y ajustar el tiempo de lo narrado al tiempo de lo dicho (o acontecido, que, al ser una entrevista con diálogo, es casi lo mismo que lo dicho), con el añadido de alguna acotación sobre actividades kinésicas y paralingüísticas, asimismo muy bien anotadas por el personaje narrador. Pero de tal entrevista, que actúa como marco diegético, se siguen en esta novela a modo de hipodiégesis los relatos de la historia de las relaciones de Juan D. con su madre, que se convierte en el asunto fundamental de 
que trata el diálogo, y una breve historia personal de Krugger, el interlocutor, que se va entreverando poco a poco a lo largo del desarrollo del marco diegético de las entrevistas. Hay, pues, en Amado monstruo dos hipodiégesis insertadas en el marco diegético de la conversación entre Juan D. y Krugger, conversación que se narra en el momento actual y para la que esas hipodiégesis son analepsis temporales. La historia del hiporrelato fundamental - las relaciones de Juan D. con su madre - se reduce a cinco días en total (sabiamente ordenados por el narratario de esa historia, Krugger, en página 22, al ofrecer un modo de resumen de los tres primeros días) y limitadas el resto de las páginas - desde la 22 hasta el final de la novela - al último día de la relación madre-hijo y a los momentos previos que antecedieron inmediatamente a la entrevista. Tal reducción - a partir de la página 22 se narra prácticamente un sólo día de la relación madre-hijo- favorece el obsesivo detallismo con que se reproducen las vicisitudes de la relación dialéctica de ambos, lo justifica; además ese relato hipodiegético se ve constantemente vigilado desde su marco, toda vez que el narrador va haciendo explícitos todos y cada uno de los tiempos (por la mañana, al mediodía, la tarde, eran las cinco, etc.) y a su vez el narratario de ese relato, Krugger, le va urgiendo a ordenar de ese modo las secuencias del relato e insiste una y otra vez sobre la hora exacta en que aconteció lo que se le está contando. Todo este sistema de vigilancia del ritmo temporal proporciona a la novela una particularísima impresión de mecanismo compacto donde toda fácil digresión es abortada y en la que la trama se desarrolla en intensidad hacia los detalles de las obsesivas y peculiares relacioncs de Juan D. con su madrc. La paradoja consiste cn que toda la novela es ella misma una gran digresión sobre una materia temática casi nimia en apariencia, detalles de tragedia doméstica, pero donde desde lo anecdótico se viaja a la indagación de insondables vericuetos de personalidades enfermizas atrapadas, como luego veremos, por un orden social que los ha esclavizado hasta reducirlos a su soledad.

En el caso, por último, de la temporalidad de La ciudad de las palomas los tiempos están administrados con precisión para los tres días de la acción, bien por el reloj «las diez de la mañana, las siete menos cuarto, etc.m en el interior de cada día, bien por el ciclo de evolución día-noche para los tránsitos de uno a otro (cf. ejemplos en páginas 1 , $11,38,39,68,89,91,98,100,101,104)$. Se puede asegurar que no transcurren nunca más de dos páginas sin una indicación del tiempo en espacios durativos de dos horas aproximadamente, hasta el punto de fijar en la página 100 el haber transcurrido unas cincuenta horas. Se logra de este modo una parcelación del devenir en tiempos cortos para una historia cuya única vicisitud es la constante y progresivamente tensa amenaza de las palomas agresoras. Una singular batalla de suceder bien reducido, pero cuya articulación detallista confiere expectativas de enorme dramatismo.

\section{La dimensión discursiva II: modalidad del decir. Juego y teatralización}

Si hasta ahora hemos analizado la peculiarísima estructura de intensidad a la que colaboran de modo igual e interdependiente el reducido espacio, la singular economía de personajes, la reducidísima estructura de la situación o pacto narrativo, la brevedad de la anécdota contada, hasta configurar todos esos rasgos un mundo narrativo de estilo particularmente arquitectónico, racionalmente administrado, el otro elemento sobresaliente del estilo narrativo de Javier Tomeo es la inteligente manera como somete todos estos ingredientes a un juego de modalidad discursiva que, por los reducidos límites a los que se somete, actúa como desafío. En efecto, todas sus novelas han partido de una dificilísima 
propuesta inicial: solamente un monólogo con casi exclusividad del estilo directo para $E l$ castillo y El cazador; la narración de una breve entrevista de dos personas en Amado monstruo y la narración de tres días de la vida de un habitante solitario en una ciudad vacía en la que apenas ocurre nada destacable, salvo la sensación de creciente amenaza por los amagos de agresividad no desatada pero sugerida de las palomas. Tan difíciles retos están resueltos con soltura gracias al buen empleo de aquello en lo que Tomeo ha demostrado ser un maestro: tanto la manipulación suelta y brillante de los discursos representados en el récit de paroles, como la brillante actitud irónica para con excéntricas situaciones puntuales resueltas con inteligencia. La ciudad de las palomas tiene menos ingredientes irónicos y humorísticos que las otras, pero en todas hay un ingrediente de teatralización al modo de juego cuyo lector modelo sería intelectualmente apelado a saborear el más difícil todavía de la propuesta discursiva.

Ya en El castillo de la carta cifrada se observan las dos constantes estilísticas más sobresalientes de Tomeo: la excentricidad del discurso, en su propio planteamiento narrativo, y la inteligente construcción de un mundo casi autónomo que explota sus propias coherencias con hábil manejo de los registros verbales. En esta novela no sólo tenemos una sola voz monologal, sino que además, propuesta como unas instrucciones que se dan al mayordomo para el desarrollo de una historia que quizá sea en el futuro, obliga al uso casi exclusivo del imperativo que genera una suerte de posibilidades que se encadenan unas a las otras, pero que se administra con sabia distinción de cada nudo o ramo. La pieza discursiva ha cifrado un juego de posibilidades cada una de las cuales genera una nueva disyuntiva o abertura de la historia. Fluye, hasta el detalle más mínimo, entre constantes alternativas que muestran una inteligencia narrativa poco común, puesto que tratándose de nimiedades consiguen sin embargo sostener la atención del lector. La excentricidad de la historia -completamente anacrónica: un marqués solitario en su castillo da instrucciones a un mayordomo para que lleve un mensaje cifrado a un conde del castillo vecino- lejos de ser arbitraria quiere justificarse a sí misma, no tanto por la justificación externa de hacernos pensar que se trata al fin y al cabo del discurso de un loco maniático, sino con la justificación interna de ser símbolo fatal de una soledad incomunicable (el mensaje de la carta es voluntariamente ininteligible). El juego está resuelto con inteligente humor y una realización verbal de impecable factura. Pensemos en que a ninguna parte llevan los vericuetos por los que discurren las sucesivas disyuntivas imaginadas (llevar la carta o no, elegir un camino u otro, vestir de este modo o de este otro, ser recibido por el conde o no serlo, estar éste en tal posición o en esta otra, etc.), pero sin embargo se sostienen en el trazado de una inteligente administración estilística en lo que se refiere al récit de paroles - y en la dosificación de los puntos de interés. Es muy eficaz en esta novela la vigilancia de los ritmos, como las tres recapitulaciones que el propio Marqués hace (vid. pág. 65) de las instrucciones, como eficaz es el uso del difícil tiempo narrativo del futuro con continuas prolepsis anticipadoras (se trata de unas instrucciones para hacer una cosa) y por último excelentemente sale el autor del difícil reto de la modalidad locutiva del imperativo presente: vas y le entregas, le dices, si te responde esto haz esto otro, etc.).

De Amado monstruo cautiva en un principio su original diseño. Sobre una construcción unitaria, ya analizada, se propone el enfrentamiento de dos colosos del lenguaje, puesto que tanto la dialéctica Juan D. vs. Krugger, que constituye el marco diegético principal, como la singular dialéctica de Juan D. con su madre, que alimenta el hiporrelato más sobresaliente de los deducidos de aquel marco, se proponen como batallas singularmente lingüísticas en las que cada personaje indaga y somete a cerco lo dicho por el otro, 


\section{JOSÉ MARÍA POZUELO YVANCOS}

conjetura sobre sus intenciones, aventura presuposiciones, en una especie de juegn. Ia tensión dialéctica no es sólo verbal; veremos que Tomeo pretende representar un caso de patología individual, pero también hacer una severa crítica a la hipocresía social; ahora bien, la fortuna de esta novela descansa en una suerte de administración metalingüística, puesto que el juego es la narración de unas conversaciones que resultan constantemente revisadas e inspeccionadas, tanto las de Juan D. con Krugger, como las tenidas con su madre. Tiene mucha importancia este matiz, porque la significación de orden psíquico y social que Tomeo pretende obtener es una especie de lucha de un David pequeño y tarado contra los Goliath del orden familiar y social (que acaban identificándose). La victoria, o principal arma para ella, de Juan D. reposa en la alta capacidad para el razonamiento lingüístico y la inteligencia verbalizadora de la que hace gala. De esta forma, por los gestos que acompañan a las palabras, por las palabras mismas y por todo el abanico de elementos paralinguísticos y semántico-presuposicionales, Juan D. logra desmontar las armas de sus adversarios, mostrar sus íntimas y mezquinas debilidades y afirmar por esa vía la hipócrita escisión que el orden social establece entre el discurso público (el que pretende sostener Krugger con su mesurada inspección inicial y el que sostiene su madre con argumentos de protección bienintencionada) y el discurso privado, íntimo, lugar de toda debilidad, sinceridad, temor o ternura reprimida (como ocurre con un Krugger poeta escondido, furtivo y persona llena de recovecos e inconfesables traumas infantiles). Como quiera que esta batalla discurso público $v$ s. discurso privado, apariencia vs. realidad, conveniencia $v s$. sinceridad, cuyo resultado final es la denuncia de la hipocresía social, se ofrece mediante el relato de una conversación en que los hechos son sobre todo palabras, el aspecto metalingüístico, el cifrado de los matices, la puntual anotación de los gestos, la eficiente dosificación de una creciente intimidad no deseada por Krugger, es el aspecto dominante en la estructura narrativa de Amado monstruo. En el plano técnico Javier Tomeo ha resuelto bien un difícil reto: la reproducción narrativa de una conversación. La amenaza era la monotonía, puesto que lograr soltura en la reiteración y variedad de diversos verba dicendi del tipo «dice», «añade», «responde», no es fácil. A ésta se suma otra dificultad: el ser la historia de Juan D. y su madre un hiporrelato en pasado respecto al marco presente de la conversación. De modo que tenemos a un narrador de su vida anterior (que consiste fundamentalmente en conversaciones con su madre) y simultáneamente de su conversación presente y ambas las reproduce en estilo indirecto. El modo de salir airoso de tan intrincada "situación narrativa" - realmente insólita en la novela española - es el hábil manejo de muy distintos, bien diferenciados y modulados verba dicendi sobre los que apoya los cambios o embragues de modalidad del decir: "dice», "le digo», «respondo que», «pregunta que», «me pide que le cuente», «añado», "se refiere a», etc. Junto a ellos, que actúan como embragues de enunciación de discursos directos de reproducción meramente conceptual, hay otros en que el discurso reproducido es parcialmente mimético, que es sin duda el modo más empleado: "Opina que mi madre es una mujer ingeniosa y que a él jamás se le hubiese ocurrido pensar... etc.». Además de la idea se da cuenta, parcialmente, de la formulación verbal que aconteció y que se reproduce parcialmente. Un tercer modo de narración indirecta es el estilo directo con un verbum dicendi introductor, a menudo entre paréntesis, como si se tratara de un discurso directo regido. Ejemplo: «En realidad (le digo) eso es también lo que yo pienso» (pág. 12). "Arriesgar la vida por un dinero que no nos pertenece (insiste) constituye un auténtico camino de santificación». De este modo, como se ve en el último ejemplo seleccionado, a menudo salva Tomeo, sobre todo cuando tiene intención irónica, la literalidad de la elocución, pues en ese ejemplo le ha interesado reproducir el discurso social comúnmente aceptado por un bien situado empleado de banca con expectativas de ascenso. Sus frases 


\section{TETRALOGÍA DE LA SOLEDAD}

reproducen toda su ideología y resultan eficazmente distanciadas respecto a los valores del narrador y presumiblemente del lector.

En lo que afecta al fenómeno de modalidad de discurso que vengo analizando, la novela El cazador de leones ha extremado notablemente los juegos planteados en las dos anteriores, al reducirse a ser la representación en estilo directo de una conversación por teléfono, de la que únicamente se reproduce lo hablado por Duvalier y a su través los silencios, respuestas y reacciones de su interlocutora. Pocos prosistas españoles podrían salir tan airosos con tan reducido mundo elocutivo. El perfecto dominio que Tomeo ofrece de la representación del decir, de las idas y venidas, silencios interpretados, coloquialismos del habla corriente, ha supuesto una alta representación artística de un diálogo telefónico. Todo lector sabe que lo narrado no es una conversación telefónica (tal conversación, stricto sensu, monológica y por teléfono resultaría ininteligible), sino la construcción de un texto en el que se administran las diversas modalidades del decir coloquial, del presuponer, el responder, del inquirir, llenando hábilmente el texto de zonas de interés o de perspicaces tránsitos del decir al narrar o desde la supuesta pregunta que mueve una evocación y desde ésta a la narración de una peripecia, etc. Piénsese que el lector, de un tirón y sin decaer un instante su atención, asiste a un monodiálogo de 95 páginas. Ello tiene mucho de buen oficio en la capacidad de teatralizar o de reproducir diálogos, pero también se salva por una bien nutrida imaginación capaz de fabular mundos muy curiosos - las supuestas aventuras africanas, por ejemplo- o hacer especulaciones llenas de comicidad sobre asuntos muy dispares (dedica por ejemplo tres páginas a hablar sobre las hienas, y otras tantas a la simbología que esconden los números y sus mágicas significaciones ignotas).

La significación de esta novela, el porqué del juego, será abordada más tarde. En lo que toca a su dimensión estilística de modulación del registro verbal es visible en esta novela un rasgo ya presente en las anteriores, pero que aquí se extrema: la cómica teatralización y el juego de contrastes grave-cómicos, de risas-veras, que Tomeo introduce por doquier. La abultada mistificación —irrisoria a menudo - que Duvalier hace de sí mismo es controlada por el agudo contraste entre el fabuloso mundo que alimenta la mistificación heroica y el prosaísmo de la interlocutora que somete al héroe a constantes recaídas en la vulgar realidad cotidiana. La comicidad de esta novela - que es mucha- adviene con frecuencia por la juntura opositiva y contrastada del entusiasmo verbal-fabulador de Duvalier y el perentorio prosaismo con que su interlocutora-oyente arrastra ese entusiasmo hasta su caída. Dice Duvalier:

Significó, en cierto modo, mi circuncisión espiritual... ¡Vaya, señorita, me está resultando $\mathrm{Vd}$. un poco materialista! Mientras yo le hablo de un rito sagrado usted piensa en problemas estomacales. ¡En efecto, la carne de león es comestible, no es precisamente tierna como un corderillo, pero puede comerse. La verdad es que no esperaba que me saliese con esa pregunta. Ustedes las mujeres, son algunas veces demasiado sensatas (pág. 32).

Hay en estos contrastes, de los que la novela es pródiga, un constante salto que ironiza el propio discurso del personaje y lo sitúa en un ámbito de fuerte teatralidad. Duvalier, lo veremos luego, se presenta a sí mismo como personaje imaginario de un libro que el mismo crea, fruto de sus lecturas. Su relación con D. Quijote es mucha y volveremos sobre ella.

En lo que afecta a otros rasgos estilísticos, los más sobresalientes son la desbordante 


\section{JOSÉ MARÍA POZUELO YVANCOS}

verborrea, fáciles sartas de requiebros amorosos, exageraciones y ponderaciones de dificultad con que Duvalier exhorta a su interlocutora a la satisfacción de una comunicación en última instancia pretendidamente erótica. La corta inteligencia de su interlocutora - que adivinamos enseguida - se disfraza en el dibujo hiperbólico e imagen teatralizada que Duvalier construye, sabiéndola falsa. El encantamiento de su verbo, como si de un prestidigitador de palabras se tratara, es el arma más fuerte de Duvalier. Por eso mismo la construcción lingüística y el oficio de mago de las palabras tiene en esta novela una importancia crucial. La medida en que el personaje es y se sabe paródico y la alta voluntad de teatralización - apoyadas en su desbordante locuacidad - la comentaré más adelante, cuando analice el conflicto singularmente cervantino que nutre la significación de esta última novela.

Repasados ya los aspectos más sobresalientes del discurso narrativo y rasgos de estilo de las novelas de la tetralogía, es preciso tratar el plano de su significación, que abordaré en cada una por separado y sucesivamente. El camino deparará enormes coincidencias entre ellas y permitirá el trazado de una isotopía de soledad.

\section{Estructura de significación}

\subsection{El castillo de la carta cifrada (1979)}

Esta novela es la excéntrica administración de un anacionismo cuyos personajes -el Marqués, el Conde-, la escenografía (castillos, salones medievales) y hábitos (relaciones feudales marcadamente caricaturescas entre amos y criados) parecen extraídos de un museo de cera. No resultan, empero, patéticamente anacrónicos, porque se advierten de inmediato pretextos para un juego de más alta significación, con intenciones que trascienden y justifican el enorme montaje de un juego llevado a la práctica entre maniáticas hipótesis sobre la recepción posible - o imposible - de una carta cifrada e ininteligible. En esta novela, precedente discursivo de las posteriores realizaciones de la que he llamado tetralogía, hay una progresiva voluntad de inmersión en el topos de la soledad e incomunicación respecto de la que estos personajes son simples agentes. Tomeo se entrega a la excentricidad de un juego metafórico con dos planos, como toda metáfora, en que el plano A, el de significación, vuelve a ser la soledad del individuo, encerrado en su fortaleza, incomunicado con el mundo y cuya carta quiere ser ....aunque fatalmente indescifrable y por ende incomunicable - un gesto de salida hacia una relación con los demás, rotas las barreras y castillos que aprisionan a sus huéspedes. Toda la novela redunda en imágenes implícitas o claramente explícitas de la soledad como un destino y una carga. La boutade final que cierra la novela sanciona que ese intento de comunicación es ya irrealizable, el gesto irónico - sarcástico más bien - que convierte la metalengua de la carta y el juego mismo de toda la novela en un camino sin salida:

Si el castillo de D. Demetrio ya no existe, si fue demolido hace veinte años para construir un bloque de viviendas sociales, si lo transformaron en un parador de turismo, si expropiaron sus propiedades para trazar una autopista, no es necesario ya que regrese para darme la noticia. Sabré entonces que me he quedado definitivamente solo y que mis tristezas no tienen remedio. $Y$ seguiré aquí con mis insectos, esos minúsculos latidos de vida que se quedaron a mitad de camino entre el mineral y el alma. Tal vez sea ése mi destino (pág. 111).

La comunicación a establecer y sobre la que diferentes pasajes de la novela insisten 


\section{TETRALOGÍA DE LA SOLEDAD}

(aunque el ser carta cifrada c inintcligible la convicrten ya en una vía ccgada, símbolo de la radical incomunicabilidad del hombre), no es posible porque ni siquiera el otro existe. Queda entonces únicamente el signo, el cifrado, el juego de significación que logra ser la novela cuya almendra es un mensaje enviado para ser leído por nadie en ninguna parte. Hacia ese plano A, de significación, al que contribuyen las diferentes recurrencias explícitas sobre la soledad (cf. págs. $58,63,75,93$, etc.) se orienta el juego significante del plano B: el juego de la carta y la historia que rodea su lectura posible, meticulosamente seguida en sus previsiones mínimas y jocosas situaciones. Adquiere este juego tal relieve y curiosa comicidad y es tanto el ingenio estilístico verbal desplegado, que alcanza a empalidecer incluso la conexión metafórica entre ambos planos y abre la novela al triunfo definitivo -quizá pretendido por el autor como irónica postulación de una comunicación imposible- del mero juego, del devenir de las mil y una alternativas sobre la presencia o no del Conde, sobre su cortejo, de si la rana será seleccionada, si saltará del bolsillo o no y si lo hará a tiempo, etc., etc. Para nada sirve saber si finalmente todo ese anacronismo $-\mathrm{y}$ el laberinto verbal que lo sirve - tiene una salida que lo justifique. Al justificarse sólo hace quizás gratuita la significación metafórica misma.

\subsection{Amado monstruo (1985)}

La lucha verbal que emprenden los personajes de Amado monstruo y la curiosa indagación metalingüística a que se entregan es al mismo tiempo un trasunto del fuerte debate del personaje para con el orden social que representa el Banco, su Jefe de Personal, Krugger, y la madre sobreprotectora y represiva. Orden social y orden familiar pretenden anular a un individuo, Juan D., cuya única y mejor arma de defensa es su sorprendente capacidad de representación metalingüística y poder de verbalización. De esa batalla, y con el utillaje de su verbo, sale Juan D. victorioso en el momento en que logra desenmascarar el rígido automatismo del orden social que no permite tara física ni debilidad; tener seis dedos en cada mano es símbolo de una diferencia intolerable para el Banco y para su Jefe de Personal, cuando en el curso del debate hemos visto a este último desenmascarado, puesto que ni es ni puede ser el personaje ecuánime que aspira a representar. El desenlace es la culminación de toda la dialéctica de la novela, que enfrenta lo privado y lo público, lo inadmisible y lo tolerado, la sinceridad no permitida (pero siempre añorada, incluso por el Krugger poeta solitario y furtivo) y la conveniencia. En el proceso de desenmascaramiento de ese orden hipócrita, que ocupa toda la conversación, se establece un juego de capturas y huidas en que el cazador y víctima son alternativamente los dos interlocutores y donde lo no permitido es lo que a borbotones va saliendo: el espacio verdadero de las debilidades, temores y ternuras que ni uno ni otro pueden permitirse. La sociedad bien organizada se puebla de individuos llenos de disimuladas debilidades y hasta de inconfesables culpas (como la de Krugger con la responsabilidad de la muerte de su propia madre), pero no puede permitir en cambio la debilidad oficial de tener seis dedos en cada mano. Desvela Tomeo esta hipocresía, presente por doquier en las caricaturas verbales y kinésicas que paulatinamente ofrece del ejecutivo (la escena de Krugger hablando con sus jefes por teléfono es patéticamente veraz), el ocultamiento tras el disfraz convencional y cada vez más inútil de su emotividad, el gusto por someter a Krugger a un cliché social altamente autosatisfactorio, como cuando afirma de él Juan D.:

Piensa, por ejemplo, que custodiar la fortuna de los demás a cambio de un salario reducido, exige, en quienes la custodian un elevado espíritu de sacrificio y un altruismo digno de elogio (p. 12). 


\section{JOSÉ MARÍA POZUELO YVANCOS}

Elige Tomeo unas veces la ironía (en la que se muestra más eficaz), otras veces la parodia y a menudo la cruel caricatura, sobre todo para con la imagen de la madre de Juan D., quien resulta en extremo teatral. Mejor resulta la gradación con que va asomando tanto la debilidad intima de Krugger, como el cambio de rol de poder en la dialéctica de dominio que entablan los interlocutores y que ofrece un singular juego de límites entre lo que a cada uno corresponde decir por su estatus y situación y la comunicación íntima o flujo de sentimiento de soledad y la exploración de los insondables misterios escondidos en sus raíces intimas de complejos inconfesables.

Resulta, empero, difícil valorar en sus justos términos èl grado de compromiso de Javier Tomeo para con sus criaturas, porque camina siempre en viajes de ida y vuelta, desde el sentimiento desnudo a la mueca teatral. Queda claro, por ejemplo en página 51 en que Krugger se revela amante y lector empedernido de poesía, un poeta-secreto en una institución bancaria, poco proclive a promocionar a sentimentales. Pero no deja de ser éste, como otros muchos en Tomeo, efectos o golpes de enorme teatralidad, de contornos dentro de un tópico: el gris funcionario que ocultamente lee sus poemas. Incluso colabora a esta teatralidad el modo como es confesada tal debilidad:

Acepto su confesión como un hecho lógico y me intereso por el tipo de lectura que prefiere. Lo mío, sobre todo es la poesía, susurra. Lanza una temerosa mirada circular para comprobar que nadie ha oído sus palabras y nos quedamos callados, mirándonos a los ojos, como dos antiguos cristianos que se han reconocido de pronto entre una turba de infieles. Me pide, luego, discreción. Dice que, al fin y al cabo, pertenece a la plantilla del Banco y que por razones obvias no puede prescindir de su empleo. Está obligado a mantenerse en la clandestinidad, en cierto modo pertenece a la poesía secreta (págs. 51-52).

La exagerada nota paródica y los tintes sarcásticos con que Tomeo acentúa su sátira social son pretendidamente tópicos. Parece como si el lector de sus novelas hubiera de entrar en la complicidad de admitir la exageración de un perfil o de un tópico con la condición de conocer que lo que a Tomeo interesa es realmente el fondo de verdad que se esconde tras el artilugio escénico de la teatralidad. Hay en esta actitud algo cervantino: sus personajes no son por ser caballeros andantes o escuderos menos hombres, pero lo que de caricatura alcanzan, al reconocerse tal y presentarse paródica, revelan el perfil de su rostro verdadero y ayudan, salvada la distancia de la parodia, a percibir su fondo de ternura, el rostro que fue el punto de partida.

\subsection{El cazador de leones (1987)}

Si en Amado monstruo el cervantismo fue un mero fondo, El cazador de leones es una divertida pero seria manifestación de la literatura como medio de salvación individual y como cárcel incomunicable que condena a su protagonista a la soledad. Armando Duvalier es un personaje ficticio que se crea a sí mismo como héroe y pretende seducir con sus inventadas historias, su capacidad de fabulación y prodigiosa verbalidad a su ingenua interlocutora. Difícil salto e imposible tránsito, porque la literatura que el personaje es - su ser de papel - resulta absolutamente intransitiva para con la vida real. Reducido a su condición de héroe idealista, es salvado y admirado: sin embargo, reconocido como hombre real - con todas sus taras, incluso la de tener seis dedos en cada mano o la de ser un reprimido sexual y un inadaptado social-, es radicalmente rechazado. El cazador de leones es la historia de una seducción fracasada, porque la dimensión heroica del personaje - como literaria e inventada - resulta incomunicable con la existencia cotidiana. 


\section{TETRALOGÍA DE LA SOLEDAD}

Ll personaje Duvalier no es creíble, ni siquiera sabemos su verdadero nombre, se ha creado una historia, una profesión y un nombre, "Duvalier, con v. de victoria", para la metamorfosis del mismo amado monstruo débil, con seis dedos en cada mano, tierno y temible poseedor de un discurso y una capacidad lingüistica privilegiada. Si el hombre es el mismo de la novela anterior, también lo es el escenario: la soledad de la habitación en la gran ciudad, incomunicado con sus semejantes y entregado a los ejercicios de su imaginación, mientras fuera cae una lluvia pertinaz y mansa, metonimia de su fría soledad. Las fugas imaginativas, los arrebatos líricos, el melodramatismo y la peculiar teatralidad que caracterizan a Duvalier conviven simultáneamente con un reprimido lirismo, cuyas únicas manifestaciones son teatralizadoras y paródicas y que sólo por momentos percibimos desnudo y sincero. El eje constructivo dominante de El cazador de leones es la esquizofrenia que separa realidad y sueño, soledad y amor-deseo, pobreza de una condición física y social y riqueza fantaseadora. Si esquizofrenia hay en el personaje - resuelta finalmente por la abierta declaración de su problema sexual, que ibamos percibiendo poco a poco en sus alusiones, paulatinamente menos tímidas y cada vez más atrevidas hasta sus procaces osadías finales- esquizofrenia hay también en el desarrollo de su discurso, pues tras la delicadísima y por momentos exquisita galantería de la que quiere hacer gala se advierten latiguillos de obsesiva recurrencia al campo erótico o al desprecio que realmente le inspira su interlocutora a la que sabe infeliz e inculta y para la que en cambio ha querido construir una imagen idealizada. Toda la novela es la administración de este doble plano; intención oculta y verbalización ocultadora a modo de máscara, pero que deja traslucir progresiva y meticulosamente desarrollada como un crescendo la aparición del monstruo de soledad urgido por el deseo sexual tras el oculto velo del romántico fantaseador y exquisito galán que finge ser.

La novela desarrolla tres planos de significación, que se corresponden con tres mundos: a) el mundo de lo ideal imaginado: la larga serie de anécdotas y episodios sobre su actividad de cazador en la lejana y mítica África de los leones, de ribetes muy caricaturescos e hiperbólicos. Los inventa Duvalier, su protagonista, y su nombre mismo y toda su personalidad, en este mundo, es inventado; b) el mundo de lo real cotidiano: paulatinamente emerge, por informaciones ofrecidas, el dibujo de un hombre solo, incomprendido e incomunicado en una ciudad hostil, sin amigos, con una madre posesiva y sin otra experiencia amorosa que su acoso repetido a mujeres solas a través del teléfono, y c) el mundo de lo real deseado: el amor solicitado a su interlocutora, que al mismo tiempo goza de atributos de los dos mundos anteriores, pues procede de una heroico-romántica, por momentos ridícula y a veces tierna mitificación de la mujer interlocutora, a la que crea como Dulcinea, personaje ideal; pero simultáneamente responde a la urgente necesidad de resolver su insatisfecho deseo erótico.

Toda la novela es un continuo desplazamiento de un mundo al otro, en el que el tercero, el de lo real deseado, aparece con más frecuencia cada vez, in crescendo y con virulencia mayor, cuanto mayor es el deseo de su interlocutora de no comprometerse. El juego de mundos imaginados y su contraste con los cotidianos, toda la mascarada en la que Tomeo va de lo paródico a lo serio, del florete verbal al grito de soledad, del quijote aventurero al pobre diablo acomplejado, tiene una explicación y el sentido metaliterario del libro va haciéndose explícito: Duvalier es todo él Literatura, producto de ávidas lecturas de libros de viajes fantásticos, donde ha construido para sí la imagen de un héroe que él mismo sabe incierta. De ahí que el tránsito de lo lírico a lo jocoso y desde el cartón-piedra de muchas de sus declaraciones a la honda seriedad de muchas otras, ese tránsito, insisto, se hace fácil porque el eje dominante es la irónica distancia con que se 


\section{JOSÉ MARÍA POZUELO YVANCOS}

construye y desconstruye el mundo imaginado, de inocultada artificialidad, que para nada podríamos tomar en serio, dada su base literario-fantástica, pero que esconde un fondo de ternura, acentuado por las desnudas declaraciones del héroe sobre su mundo real cotidiano, parecido al del hombre medio y gris habitante de cualquiera de nuestras grandes ciudades, pero entregado a la diferencia de ser literatura. El triple plano que favorece la transición de un mundo a otro convive además con la sabrosa mixtura de anécdotas, ingeniosas ocurrencias, comparaciones insólitas, estrafalarias deducciones y verbalidad enjundiosa y desbordante.

Acabaré el comentario de la estructura significativa de esta novela con el dibujo $-\mathbf{a}$ grandes pinceladas - de la que creo su temática radical: la dimensión metaliteraria de la novela, que, como dije, termina por ser un homenaje al Quijote cervantino. Este Duvalier heroico de dimensiones más altas, aventurero y arriesgado cazador de leones es un ser de papel que se sabe a sí mismo de papel. Es más, conoce Duvalier que la imagen que de sí mismo crea es fruto de su opción por la lectura literaria de héroes fabulosos como compensación imaginativa a su terrible soledad y frustración. Así lo declara en pp. 38-39:

Los pueblos que carecen de leyendas (y esto lo dijo alguien mucho más importante que yo) están condenados a morir de frío. Creo más en las leyendas que en la verdad poética, proclamaba un poeta. Pero ustedes, los que viven en la gran ciudad han aprendido a prescindir de ellas o las han sustituido por otros mitos que huelen a petróleo... Se sientan entonces frente al televisor y tratan de encontrar el olvido entre montañas de cartón piedra y selvas de jardinería que en nada se parecen a las verdaderas. Sólo de vez en cuando suena el teléfono o reciben alguna carta y entonces se consuelan pensando que, a pesar de todo, no se han quedado completamente solos.

Duvalier es un quijote menos noble y desinteresado que el cervantino. Alcanza, eso sí, a prccisar consciente y explícitamente su dimensión libresca y las razones de su pasión por la lectura, la única capaz de hacerle «acariciar en sueños la Luna con la punta de los dedos» (p. 40). Llega Duvalier a hacer un retrato de sí cuando dice: «Soy, como suele decirse, un lector impenitente. Aquí en mi residencia de la ciudad tengo más de cinco mil (libros)». «Lo que más abunda en mi biblioteca - añadirá en página 58 - son los libros de viajes y las narraciones maravillosas». "Ahora mismo le estoy hablando desde una habitación repleta de libros... y le aseguro que los he leído todos. ¿Sabe qué significa eso? Pues significa, sencillamente, que no he necesitado salir fuera de los límites de este cuarto para saber todo lo que sé ahora. Los libros, mirándolo bien, son como ventanas abiertas en nuestra casa a los más variados paisajes. Pero no debiera extrañar a nadie que un hombre gordo y solitario, con las pantorrillas atormentadas por las varices y que apenas puede ver más allá de sus narices y que además (sí, sí, también eso) se pasa casi todo el día encerrado en su habitación pueda saber tanto como el más intrépido de los viajeros... Yo también, aunque no tenga nada que ver con ellos, prefiero a esos hombres solitarios, hijos de la reflexión y del silencio, que son capaces... de transformar su humilde mundo a golpes de imaginación y fantasía... Conozco a algunos de esos hombres. Se los encuentra uno por casualidad...) (págs. 42-43).

En tales textos, Duvalier, además de retratar su verdadero rostro, ha revelado la clave del libro: la capacidad de ser otro y de vivir la vida de la fantasía literaria como salvación o escape de su sórdida y anodina realidad. El cazador de leones es la historia de un lector empedernido de libros de viajes fantásticos que quisiera crear una comunicación entre ese mundo soñado y el suyo real, por el expediente de crear en su interlocutora 
un personaje, también ficticio, que satisfaga en liberalidad, inteligencia y pasión erótica todas sus necesidades. Fracasa Duvalier en el intento de ese trasvase de la literatura a la vida porque ésta es mucho más vulgar y está aquejada de miopía para con el generoso mundo de la fantasía. Armando Duvalier hubiera querido, por medio del trasvase de la literatura a la experiencia cotidiana:

Renunciar a ese veneno que llamamos sentido común. Yo tuve también (lo reconozco) mis dosis de sentido común, pero un día lo comprendí todo. Me dije: cuidado Armando porque hoy los locos son aquéllos que se empeñan en ver molinos de viento donde sólo hay gigantes. $\mathrm{Y}$ a partir de ese descubrimiento pude ya enfrentarme con mis números, prescindiendo de toda lógica, de la racionalidad, del análisis, de los principios. Sí, Rosaura, puede usted estar convencida de lo que le digo: la gente es sólo lo que sucede en sus mentes... (p. 68).

\subsection{La ciudad de las palomas (1989)}

La tetralogía se cierra con La ciudad de las palomas, novela discursivamente alejada de las otras tres y que podríamos considerar ajena a la unidad que aquéllas decididamente tienen, si juzgáramos únicamente a partir de estructuras formales, pero que, mirada a la luz de la significación recurrente de la soledad del individuo encerrado bien en su castillo, bien en sus fantasmas histórico-infantiles, o bien en su fantasía particular, alcanza a ser un broche o culminación de las vetas abiertas por las otras. Porque La ciudad de las palomas es toda ella una novela simbólica que parte de una situación insólita, de influencia kafkiana: la ciudad, de repente, se ha quedado absolutamente vacía. Sin explicación alguna todos se han ido y la única vida que queda es Teodoro, el personaje focalizador, y las amenazadoras palomas que se adivinan peligrosas y agresivas. Toda la novela es la crónica de su enfrentamiento con las palomas y de las salidas imaginadas por Teodoro para sobrevivir en una ciudad que, sin embargo, inexplicablemente, se resiste a abandonar (el reproche de no rebajarse a ir en busca de los que le han abandonado es bien débil y poco verosímil). Lo importante para Tomeo ha sido trazar el cuadro de una soledad y la isotopía de desolación y muerte cruza la novela, desarrollada toda ella en el espectral silencio y sin ningún otro cauce comunicativo que un teléfono sin respuesta y un ordenador que deja de funcionar. El conflicto, la lucha entre agresor (las palomas) y el personaje víctima, es lucha paulatinamente sugerida por medio de connotadores que alcanzan a dibujar un clima de temor y de amenaza no concretada. Hay en el modo de describir a las palomas una creciente capacidad de connotación por su masiva actitud de acoso y su cada vez más evidente consciencia de un raciocinio o instinto de agresión como el de un ejército programado por no se sabe qué fuerza superior para destruir al único hombre superviviente en la espectral ciudad. Ésta no tiene nombre. Se llama B y se encuentra entre las ciudades de A y de C. Las carreteras van hacia el Norte o hacia el Sur y a ninguna parte llevan. Todo queda reducido a un espacio de virtuales connotaciones simbólicas: cualquier ciudad tiene lo que ésta posee y su límite no es nunca el de la realidad histórica, sino el del espacio simbólico. Fuerzas ignotas y superiores han decidido ya un destino.

En esta novela Tomeo ha acentuado las notas de lirismo ya presentes en las anteriores, allí de modo aislado y aquí con frecuencia. Por tres vías llega tal lirismo al lector: a) el contraste que en ambientes muy hoscos ofrecen inesperadas declaraciones de sentimientos: «Puede incluso que ahora mismo estén acusándole de ser el único culpable de su propia soledad y diciéndole que fue él quien se escapó de los demás y no al revés, dejándolos 


\section{JOSÉ MARÍA POZUELO YVANCOS}

con la certeza de su desamor»; b) La frase poética de índole irracional, que emerge en un contexto inesperado: «Podrían alcanzarlo en un abrir y cerrar de ojos... pero no recurren a las alas, como si hoy tuviesen el cielo prohibido" o los espacios evocados en página 42 , mágicas imágenes en la pantalla de un ordenador, y c) la tremenda imagen de desamparo y soledad que ofrecen los personajes referidos: una portera de un inmueble, desahuciada por los médicos y con la única asistencia abnegada de su compañero que se resiste a dejarla abandonada; la madre intentando en la mesita del teléfono solitarios imposibles...

Toda esta atmósfera de tristeza desolada va llenando los espacios interiores de un gran cuadro de alcance simbólico sobre el individuo urbano, condenado a la que hemos visto isotopía textual dominante de la narrativa de Tomeo: la inevitable soledad. 